\title{
DEVERIAM OS CORTADORES DE CANA-DE-AÇÚCAR SE QUALIFICAR? MODIFICAÇÕES E PERMANÊNCIAS NO TRABALHO AGROINDUSTRIAL NO TRIÂNGULO MINEIRO
}

\author{
Sérgio Paulo Morais ${ }^{1}$ \\ Denise Nunes De Sordi ${ }^{2}$ \\ Não Importa quantos o Imperador esmagou. \\ $O$ historiador científico \\ (embora tenha notado a contradição) afirma que a força \\ produtiva aumentou. \\ E. P. Thompson
}

\section{RESUMO}

$\mathrm{O}$ artigo aborda problemáticas referentes à qualificação de trabalhadores das lavouras sucroalcooleiras em contraponto com mudanças e transformações no trabalho agrícola, Tem por objetivo propor alguns caminhos para lidar com a temática, ao abordar aspectos conjunturais e as experiências vividas pelos sujeitos. O procedimento de investigação foi mediado por fontes oficiais, jornais de circulação regional e nacional e entrevistas realizadas com trabalhadores.

Palavras-chave: Trabalhadores; cana-de-açúcar; qualificação, movimento sócio-espacial; mecanização.

\section{SHOULD BE THE WORKERS IN SUGAR CANE QUALIFY? MODIFICATIONS AND STAY AT WORK AGRO INDUSTRY IN TRIÂNGULO MINEIRO.}

\begin{abstract}
The article is about the problems of professional qualifications of workers in sugar cane plantations in counterpoint to living and working conditions in counterpoint to changes in the production and employment agricultural. And has the goal of proposed ways of coping with the thematic, analyze the social and the experiences of subjects involved in process. In the research process were used official sources, newspapers and interviews conducted with the workers.
\end{abstract}

Keywords: Workers; sugar cane; professional qualifications; social-area activity; Mechanization

\section{Apresentação}

A questão contida no título deste artigo refere-se, por diferentes razões, ao questionamento proposto por Eric Hobsbawm (2000, pp.399-416) em: "Deveriam os pobres se organizar?", texto escrito originalmente nos finais da década de 1970. Partindo 
de uma obra produzida nos Estados Unidos, o historiador marxista apresenta contundentes reflexões sobre mobilizações circunstanciais de "pobres" frente a potencialidades de organização dos mesmos em entidades, sindicatos ou agrupamentos estáveis.

Porém, ao propormos a questão-título não faremos um balanço sobre possibilidades de melhorias individuas de vida de trabalhadores por intermédio de diferentes meios de ensino-aprendizagem. De maneira distinta, ao aproximarmos nosso título da indagação feita por Hobsbawm buscamos apresentar conjunturas e conjecturas que têm indicado a necessidade de melhor preparação da força de trabalho para exercer uma atividade que durante séculos foi (e ainda é) realizada por intermédio de força física.

Este processo é aqui analisado no âmbito de mudanças decorrentes de leis que visam proibir queimadas e do advento de mecanização no corte de cana-de-açúcar. Situações que, em termos oficiais, implicarão, em curto período de tempo, em "ganhos ambientais, como a redução da emissão de dióxido de carbono (CO2), incentivo ao uso da palha da cana para produção de energia e o desenvolvimento sustentável do setor sucroalcooleiro." (AGÊNCIA MINAS, 26 ago. 2008)

Com o objetivo de colocar em perspectiva histórica as contradições que se projetam utilizamos evidências, reflexões acumuladas e algumas entrevistas realizadas com trabalhadores rurais pelo estudo "Histórias, Memórias e Cidadania: Estudo Sobre os Fluxos Migratórios de Trabalhadores para o Triângulo Mineiro ${ }^{3}$ nas Últimas Décadas”, apoiado pela Fapemig (2008-2010) e coordenado pelo professor Paulo Roberto de Almeida (UFU) e por fontes referentes à pesquisa "Os Trabalhadores das Lavouras de cana-de-açúcar na região de Tupaciguara - MG frente à expansão das usinas sucroalcooleiras no Triângulo Mineiro (2007-2011)" de Denise Nunes De Sordi, mestranda em História na Universidade Federal de Uberlândia.

Para além de questões ambientais e de certificações internacionais, tal como indicaremos a seguir, a mecanização se anuncia como importante via para qualificação de mão-de-obra,

Com a mecanização, a máquina colhedora de cana realizará o trabalho de cerca de oitenta pessoas. Com isso, os trabalhadores que não serão aproveitados deverão ser qualificados para assumirem novos postos de trabalho. Vários empreendimentos do setor já deram início à requalificação e planejam o aproveitamento dessa mão-de-obra em outros setores. O incentivo aos cursos de capacitação e requalificação da mãode-obra que trabalha nas lavouras de cana, por parte do poder público e do setor privado, é uma exigência do protocolo. Uma das estratégias previstas no documento é a intensificação de políticas públicas de incentivo à agricultura familiar. A fiscalização do cumprimento do protocolo ficará a cargo do Sistema de Meio Ambiente (SISEMA). De acordo com o presidente do Conselho de Administração do Grupo Moema, Maurílio Biagi, as duas usinas que o grupo paulista possui nas cidades de Itapagipe e Frutal, no Triângulo Mineiro, já têm $70 \%$ da produção mecanizada. "Estamos investindo na requalificação dos trabalhadores, dando educação e instrução". As duas indústrias empregam 4 mil pessoas no parque industrial e na área de lavoura (AGÊNCIA MINAS, 26 ago. 2008)

Em julho de 2009, o Governo Federal brasileiro, em conjunto com diversos setores da sociedade, dentre eles empresários, Ministérios e Confederações dos trabalhadores rurais e da Agroindústria, aprovou uma minuta de acordo para "humanizar" as condições de trabalho de cortadores manuais de cana. Dentre outros objetivos, o documento buscava 
garantir condições de trabalho decentes para o emprego nas lavouras. "O Compromisso [...] visa garantir novos direitos e melhor qualidade de vida para os trabalhadores da lavoura da cana-de-açúcar" (COMPROMISSO NACIONAL PARA APERFEIÇOAR AS CONDIÇÕES DE TRABALHO NA CANA-DE-AÇÚCAR, 2009, p.3).

O documento, cuja adesão por parte dos empresários seria apenas "voluntária", pautou uma agenda de questões relativas a 18 temas:

contrato de trabalho; saúde e segurança do trabalho; transparência na aferição da produção; alojamento; transporte; migração; escolaridade, qualificação e recolocação; remuneração; jornada de trabalho; alimentação; trabalho infantil e trabalho forçado; organização sindical e negociações coletivas; proteção ao desempregado, com atenção aos trabalhadores no corte manual no período da entressafra; responsabilidade sobre as condições de trabalho na cadeia produtiva; responsabilidade no desenvolvimento da comunidade; Programa de Assistência Social - PAS da atividade canavieira; trabalho por produção; trabalho decente e trabalho análogo ao escravo. (Idem, 2009, p.4).

No que tange à "escolaridade; qualificação e recolocação", as indicações ficaram por conta da "CLÁUSULA TERCEIRA: DAS POLÍTICAS PÚBLICAS", na qual se estabeleceram as ações que deveriam ser realizadas pelo Governo Federal. Entre elas, destacam-se

promover a alfabetização e elevação da escolaridade dos trabalhadores do cultivo manual da cana-de-açúcar; promover a qualificação e requalificação dos trabalhadores do cultivo manual da cana-de-açúcar, com vistas a sua reinserção produtiva; e fortalecer ações e serviços sociais em regiões de emigração de trabalhadores para atividades sazonais do cultivo manual da cana-de-açúcar." (Idem, 2009, p.11-12)

No texto do "Compromisso Nacional" também se afere que

a atividade sucroalcooleira é uma importante geradora de emprego e renda no Brasil: um milhão e 260 mil empregados formais diretos em 2007, 70\% deles na região Centro-Sul do País (ver quadro de empregados no setor). Na produção da cana-de-açúcar, havia cerca de 498 mil empregados formais diretos em 2007, $83 \%$ deles na região Centro-Sul. $\mathrm{Na}$ lavoura da cana, sobretudo na colheita manual, boa parte dos empregos é de pequena qualificação e temporário, com níveis distintos para os períodos de safra e entressafra. Os trabalhadores formais empregados na produção da cana têm um perfil jovem e um perfil de escolaridade relativamente baixo. Quase $91 \%$ deles têm até 50 anos, cerca de $28 \%$ entre 30 e 39 anos ou são mais jovens (cerca de $24 \%$ entre 16 e 24 anos). A maior parte não concluiu o Ensino Fundamental (atualmente de nove anos), cerca de $52 \%$ têm até quatro anos de estudo e cerca de 7\% são analfabetos (Idem, 2009, p.17).

Exploraremos com acuidade algumas das informações indicadas, no momento, entretanto, registramos as motivações finais do documento, que, dentro do âmbito do "Diálogo Social para Humanizar o Trabalho" (COMPROMISSO NACIONAL PARA APERFEIÇOAR AS CONDIÇÕES DE TRABALHO NA CANA-DE-AÇÚCAR, 2009, 
p.1), revelou preocupação com o desemprego e com a presença maciça de milhares de trabalhadores sazonais.

Com a acelerada inovação tecnológica, em particular a crescente mecanização da colheita da cana, tem ocorrido uma menor necessidade relativa de força de trabalho e um aumento da capacitação requerida dos trabalhadores. Cada colheitadeira introduzida substitui de 80 a 100 trabalhadores no corte de cana, dependendo de seu tipo, provocando a perda de uma grande quantidade de postos de trabalho, e agravando assim a situação de um segmento de trabalhadores com perfil relativamente baixo de escolaridade e capacitação, e com poucas chances de obter empregos de melhor qualidade. Com a maior mecanização e com a extensão do período das safras, a sazonalidade dos empregos vem também diminuindo na lavoura da cana. Muitos desses trabalhadores migram temporariamente para regiões canavieiras no período de colheita. Na condição de principal polo sucroalcooleiro do País, o estado de São Paulo absorve os maiores contingentes de trabalhadores migrantes temporários. [...] As ações previstas no Compromisso Nacional procuram justamente consolidar e ampliar as melhores condições de trabalho na lavoura da cana-de-açúcar e enfrentar o impacto da mecanização sobre o nível de emprego. (Idem, 2009, p.19)

Neste sentido, buscaremos recompor discussões localizadas no debate sobre tais aspectos, a partir das trajetórias, experiências e práticas dos sujeitos envolvidos com a finalidade de não enxergá-los à margem desse processo de mudança. Porém, antes discutiremos algumas nuances teóricas e políticas que se colocam em torno do que apresentamos até então.

\section{Trabalho, trabalhadores e qualificação}

A relação existente entre qualificação de trabalhadores e "mercados" de trabalho possui robusta bibliografia. No campo crítico da produção acadêmica, diversos autores (CURY, 1985; JANTSCH, 2001; SEGNINI, 2000; e outros) têm notado "insuficiências", contradições e relações dialéticas nas quais a qualificação, em diferentes níveis, poderia emancipar os trabalhadores das explorações impregnadas em relações de trabalho e no social, já que

a educação torna-se fundamental como um fim em si mesma, como condição sine qua non para a cidadania crítica, [...]; vinculá-la ao trabalho sem mediações tem sido relevante para culpar as vítimas [...] ou legitimar ações políticas que possibilitam a 'ilusão de desenvolvimento' (ARRIGHI, 1997, Apud SEGNINI) sem alterar a ordem social desigual (SEGNINI, 2000, p. 80)

O reconhecimento da qualificação como fundo social cidadão em contraponto aos ditames de uma "Nova Ordem Mundial", estabelecida desde os anos 1990, possui também peso e significado em meio a obras acadêmicas (FRIGOTO, CIAVATTA, 2003; HADDAD, GRACIANO, 2004).

Visto que:

[...] a ênfase da cidadania recai sobre o 'cidadão produtivo' sujeito às exigências do mercado, onde o termo produtivo refere-se ao trabalhador 
mais capaz de gerar mais-valia. $\mathrm{O}$ que significa submete-se às exigências do capital que vão ao sentido da subordinação e na da participação para o desenvolvimento de todas as potencialidades. (FRIGOTTO, CIAVATTA, 2003, pp.52-53)

Gaudêncio Frigotto e Maria Ciavatta (2003) ao explorarem os sentidos e historicidades da noção de cidadania, contrapõem o aspecto individual e liberal que cerca o termo à possibilidade emancipatória (2003, p.55) - potencialmente contida em um arranjo "coletivo", distinto do que se tem na perspectiva de mercado. Portanto, a condição para além do indivíduo "produtivo" está ainda a ser estabelecida, pois,

o conceito de educação do homem integrado às forças sociais difere da mera submissão às forças produtivas. Esta concepção distancia-se dos cursos breves de educação profissional - a exemplo do Plano Nacional de Qualificação do Trabalhador (PLANFOR) ${ }^{4}$ - descontextualizados de uma política de desenvolvimento, geradora de trabalho, emprego e renda e de políticas sociais que sinalizem a melhoria de vida da população e mudança de rumo na falta de perspectiva para os jovens e adultos desempregados. (FRIGOTTO, CIAVATTA, 2003, pp. 57-58)

Tal como informamos, tentaremos recompor condições existentes, para explorarmos dimensões sobre o tema do trabalho e da qualificação. Na percepção dos problemas, localizamo-nos entre aqueles que buscam nas complexidades do vivido, a concepção materialista da história, que, a saber, "seria a produção e a reprodução da vida real" o "fator que em última instância determinaria a História" (ENGELS,1986, p.134), situação que obviamente não exclui perspectivas futuras de transformação social.

O termo "qualificação" é apresentado na atualidade, tanto pelo governo, quanto pelos senhores do agronegócio, como o combate à alfabetização de uns, necessidade de ensino fundamental para outros, facilitação de carteiras de habilitação em máquinas para terceiros etc. A nosso ver, esta dinâmica incerta, por um lado, termina por culpabilizar "os pobres por suas pobrezas" (GENTILI, 1996, p. 22), ou os indivíduos por suas trajetórias pessoais de vida. Por outro, contribui para do processo de degradação do trabalho no campo. Situação materializada em baixos salários para os que não possuem estudos.

No avançado estágio tecnológico do agronegócio brasileiro, "qualificar" diz respeito a algo bastante distinto de buscar modos de alfabetizar os seus trabalhadores, tal como projeção apresentada e pretensamente assumida pelo Governo Federal.

A primeira vista, pensamos na mecanização do plantio e da colheita como processo tecnológico final à produção da cana-de-açúcar; entretanto, existe uma complexidade de maior monta:

a Enalta, empresa de tecnologia para o setor sucroalcooleiro sediada em São Carlos (SP), foi a única brasileira a aparecer no ranking de inovação da revista norte-americana "Fast Company". A lista anual da publicação destaca as 50 mais inovadoras do mundo. A Enalta ficou em $43^{\circ}$ lugar e é cliente FINEP - ela foi apoiada com R\$ 2,683 milhões por meio do Programa de Subvenção Econômica. [...] Em 2008, em parceria com o CENA/USP de Piracicaba, a empresa começou o desenvolvimento do projeto Aquavin, com o apoio do Programa de Subvenção Econômica da FINEP. O projeto visa aumentar a produtividade da cana-de-açúcar por meio da aplicação controlada de vinhoto (subproduto da fabricação do etanol nas usinas). A ideia é melhorar o processo de fertilização do solo e nutrição da cultura. Em uma única operação de campo, será possível 
aumentar a eficiência da fertilização nitrogenada e a reposição do potássio na cultura, um importante nutriente. Outro projeto apoiado pela FINEP em que a Enalta atua é uma parceria com a Universidade de Campinas. Por meio de recursos do Fundo Setorial CT-Agro, foi desenvolvida uma plataforma tecnológica de agricultura de precisão para aumentar o ganho de eficiência operacional no processo de corte e colheita de cana-de-açúcar. (JORNAL DA CIÊNCIA, 7 mar. 2013.)

Não entraremos no mérito das relações entre público e privado, no que diz respeito ao financiamento e a utilização de universidades estatais ou federais para pesquisas a serem utilizadas por empresas particulares. Entretanto, a evidência demonstra um avançado processo científico realizado por uma "classe de trabalhadores de nível superior" que se "distinguem dos trabalhadores de fábricas" [ou do corte], "estando apenas agregados a eles" (MARX, 1982, p.481).

Esta realidade cria uma sólida "autocracia" (MARX, 1982, p.485), que na busca pela melhoria da produção determina, através do conhecimento científico, ações, modos e ritmos de trabalho de outros sujeitos [alfabetizados ou não] que estão no ciclo de produção de etanol ou açúcar. TEIXEIRA (2013, pp. 217-228).

Por indicação das evidências provenientes Governo Federal e das discussões em torno de outros documentos, manteremos aberta a perspectiva da qualificação, buscando dialogar com diferentes vertentes e discursos. Porém, não podemos deixar de registrar essa amplitude de significados atribuídos ao termo e as interconexões destes sentidos com as mudanças nas relações de trabalho

Durante séculos, no que diz respeito especificamente ao corte de cana-de-açúcar, os proprietários e industriais não se importaram em desfrutar dos benefícios da falta de regulamentação do emprego nas lavouras, do trabalho escravo, do migrante, da força de trabalho de mulheres, jovens e trabalhadores de meia idade. Tal como aferimos em revista própria do setor,

Um trabalho difícil, que utilizou a mão de obra indígena e negra durante muitos séculos, e que desde o surgimento do Proálcool, nos anos 70, tem atraído anualmente milhares de trabalhadores migrantes para as principais regiões produtoras, no Centro-Sul do País. Eles buscam nas áreas canavieiras o faturamento que não conseguem obter nas suas terras de origem, normalmente o Nordeste do Brasil e o Vale do Jequitinhonha, em Minas Gerais. (CLIVONEI, ago. 2011, p. 9)

Mais recentemente a substituição de trabalhadores por colhedeiras mecanizadas tem se tornado um tema comum aos grandes proprietários de terra. Segundo Emmanuel Desplechin, representante-chefe da União da Indústria de Cana-de-Açúcar (UNICA) na União Européia, que apresenta a visão deste setor da indústria brasileira, a preocupação com as condições de trabalho dos cortadores de cana, relaciona-se às preocupações e ao comprometimento do Brasil com as certificações internacionais (com destaque aos critérios de sustentabilidade da União Européia), definidas pela Organização Mundial do Trabalho (OMT) e ao sistema de organização "Better Sugarcane Initiative" (BSI). (BONSUCRO, 2008-2012)

Em outros momentos discutimos a limitação de alguns das práticas e discursos em torno destas relações. Indicamos que (i) as colhedeiras de cana não surgiram por questões de inovação tecnológicas atuais, já que estão presentes no cenário agrário desde os anos 50 (ALMEIDA, MORAIS, 2012, p. 155). Elas ocuparão um espaço no qual existem os maiores conflitos e greves realizadas pelos trabalhadores do setor. 
Verificou-se nas áreas de pesquisas do Triângulo Mineiro que ocorreram greves nos anos de 2003, 2004, 2005, 2006, 2008, pautadas principalmente no reajuste do piso salarial, que atualmente corresponde a R \$ 690,00 um dos maiores do setor na região do Triângulo Mineiro. Os trabalhadores conseguiram o fim do sistema cinco por um, com um principio de banco de horas que transformava o domingo em dia útil de trabalho. Além disso, obtiveram a garantia da estabilidade de 45 dias, a oportunidade de conferir a pesagem da cana, a correção das precariedades de seu meio transporte e a segurança de que, na ocasião de ausência do trabalhador por motivo de saúde, o mesmo deverá receber seu pagamento pela média diária de produção e não pelo preço mínimo. Aliadas as estas conquistas, os trabalhadores garantiram por meio de negociações, o direito de não serem descontados os dias de paralisação, como apoio do Sindicato dos Trabalhadores Rurais, da CONLUTAS Regional Triângulo Mineiro e Federação dos Trabalhadores na Agricultura do Estado de Minas Gerais FETAEMG (SOUZA; CLEPS JR., 2009, p. 249-264).

(ii) As queimadas, que antecedem o corte manual, não representam o único [nem o principal] transtorno ao meio ambiente (ALMEIDA; MORAIS; RESENDE, 2009, p.214); entre outros. Temos notado também que (iii) a retração do número de vagas nos canaviais, um trabalhador máquina para 80 ou 100 manuais, não permitirá a "absorção" de trabalhadores não qualificados e nem mesmo de altamente qualificados, pela simples razão (inicial) de corte de postos de trabalhos.

Sobre este último aspecto, consideramos importante salientar três condições: a) a mecanização por si só não provoca (ou provocará) a melhoria do trabalho, ou trará melhor qualidade de vida aos trabalhadores pretensamente qualificados para a utilização de tratores, colhedeiras ou caminhões. Se tomarmos as condições examinadas por autores marxistas e pelo próprio Marx, no primeiro processo de industrialização, em determinadas cidades inglesas, no século XVIII e anos iniciais do século XIX, poderíamos nos orientar por questões teóricas simples, mas ainda pertinentes às preocupações de nossas pesquisas.

Entre algumas, destacamos que "a produtividade da máquina mede-se [...] pela proporção em que ela substitui força de trabalho do homem" (MARX, 1982, p. 445). Desde os anos 1950, época em que as colhedeiras de cana chegaram ao mercado, fez possível substituir a força de trabalho manual pela mecanizada. A nosso ver, a permeância do corte manual se deu por razões de custos e de exploração do trabalhador manual.

b) Em decorrência desta situação vimos que a situação de escravidão, pretensamente comum aos "migrantes" desqualificados e endividados, passar a ocorrer em terras com plantio e corte feitos por meio de máquinas.

Em Goiatuba, Goiás, ano de 2011, cidade próxima à região do Triângulo Mineiro,

trinta e nove trabalhadores em regime análogo a escravidão foram resgatados durante operação realizada nos municípios de Vicentinópolis e Goiatuba. Os trabalhadores foram contratados para a colheita e transporte da cana-de-açúcar e eram submetidos a jornadas exaustivas de trabalho, com mais de $24 \mathrm{~h}$ seguidas de labor ininterrupto. A operação foi realizada entre os dias 27 de setembro e 14 de outubro e foi encabeçada pela Superintendência Regional do Trabalho e Emprego em Goiás (SRTE), em parceria com o Ministério Público do Trabalho (MPT), Polícia Federal (PF) e Polícia Rodoviária Federal (DPRF).Os trabalhadores ocupavam funções no corte mecanizado da cana, operando máquinas de colheita, tratores e caminhões. $\mathrm{O}$ dono da propriedade mantinha apenas 
duas equipes que se revezavam ora em jornadas de trabalho de $12 \mathrm{~h}$ (12 de trabalho por 12 de folga), em turnos de revezamento semanais, ora em turnos de $24 \mathrm{~h}$ ( 24 de trabalho por 24 de folga). Somadas as horas de percurso, cada trabalhador cumpria de 15 a 27 horas diárias de trabalho. Os horários de trabalho ultrapassavam em mais de cem por cento as jornadas estabelecidas por lei. Atualmente, todo trabalhador de cumprir 6 horas diárias, em turnos de revezamento, ou 8 horas diárias, em turnos fixos. Apesar de receberem salários, os trabalhadores não recebiam horas extras e nem os descansos semanais remunerados. Segundo os auditores, os trabalhadores já estariam sentindo os efeitos do excesso de trabalho. Pelo menos dois acidentes já teriam acontecido na propriedade, ambos envolvendo motoristas. Em um dos casos, o trabalhador adormeceu ao volante, com o caminhão carregado de cana. Ele só acordou quando subiu em uma curva de nível. Submeter um empregado a jornadas de trabalho exaustivas é classificado como uma das condições análogas á de escravo. Os auditores do trabalho emitiram trinta e nove guias de segurodesemprego para cada trabalhador Cada um receberá três parcelas de um salário mínimo cada. Além disso, eles receberão verbas rescisórias que somam R\$ 946 mil e encargos sociais (INSS e FGTS). (O POPULAR, out. 2011, s.p.).

Ao contrário do que aludem os protocolos entre governo e empresários, a máquina não trará qualificação aos que permanecerem no plantio e na colheita de cana, pois, a tecnologia desemprega, e, ao mesmo tempo, rebaixa preços de salários. (MARX, 1982, pp. 449-459).

c) O terceiro aspecto contrastante à humanização e à melhoria do trabalho, para os pretensos qualificados, diz respeito à criação de um grupo de trabalhadores que, agregados ao corte com colhedeiras, cumprem atividades de modo desregulamentado, sem carteira assinada, sujeitos a contratações diárias e à baixa remuneração. Referimo-nos às "bituqueiras", mulheres (geralmente é um trabalho feminino) que recolhem sobras das colheitadeiras, e que estão se tornando conhecidas na região do Triângulo Mineiro.

Em Canápolis, município no Pontal do Triângulo, que tem cana até no nome, a presença das bituqueiras chama atenção na paisagem da colheita na sexta maior cidade produtora de Minas Gerais. Para trabalhar das $7 \mathrm{~h}$ às $15 \mathrm{~h}$, com direito a uma hora de almoço, elas recebem diárias de $\mathrm{R} \$ 23,30$. O trabalho é literalmente pesado. Depois que a colheitadeira passa pelas ruas (espaçamento entre as linhas de cana) são colhidas, em média, cerca de 90 toneladas de cana por hectare (10 mil metros quadrados). O peso equivale a quatro cargas de treminhão. No entanto, sempre restam muitos talhos que a máquina não consegue cortar, por causa da formação da planta. "Muitas deitam", afirmou o encarregado de produção Edílson Donizete Mendonça, o Carrasquinho. [...] São 41 bituqueiras na equipe comandada por Carrasquinho. Em média, cada uma carrega cerca de 170 quilos por hectare. Em um dia de trabalho, a equipe chega a percorrer 200 hectares. [...] Em áreas que ficaram muitas plantas para trás depois que a colheitadeira passou, cada bituqueira chega a carregar 800 quilos de talhos, por dia, que são amontoados para os tratores carregarem até os treminhões. "O que as máquinas não fazem, a gente faz", afirmou a bituqueira Luiza Helena dearvalho [...]. (CORREIO DE UBERLÂNDIA (a), 31 maio 2009, p. A6) 
Sob efeitos de um "sol escaldante" e de quilos e quilos de feixes de talhos, as trabalhadoras foram apresentadas aos leitores do jornal a partir de suas subjetividades e de seus "toques femininos", deixando-nos distantes do que uma tradicional sociologia (ou historiografia) do trabalho esperaria encontrar como exploração direta da mais-valia, ou algo semelhante. (ALMEIDA, MORAIS, BARBOSA, 2011, pp. 143-166)

[...] Depois da bóia-fria na marmita, sempre dividida entre as colegas, é hora de pegar no batente novamente. $O$ toque feminino não falta mesmo no trabalho árduo (e árido) da colheita da cana. Elas não descuidam da pele e passam protetor solar no rosto e nos braços. [...] A roupa cobre todo o corpo, e há também protetores (perneiras) contra insetos peçonhentos e cobras. [...] Em comum, a maioria das bituqueiras tem sua origem no trabalho no campo. Algumas são migrantes do Nordeste, como a baiana Maria Zélia Silva. A supervisora Cida Alves, porém, é exceção. "Caloura" entre as bituqueiras, está na atividade há menos de um mês. 'Trabalhei no programa Saúde da Família (PSF) de Canápolis, por oito anos, mas mudou o prefeito e perdi meu emprego', disse. Ela é quem coordena as bituqueiras e não precisa fazer tanto esforço físico quanto as demais. 'No começo tive dificuldades, mas agora já estou me acostumando. Que atrapalha são os bichos. Tem cobra, rato, insetos' [...](CORREIO DE UBERLÂNDIA (b), 31 maio 2009, p. A6)

Afere-se, para além das questões de "beleza" e de feminidades, que tais trabalhadores que carregam em média 7 toneladas de cana/dia sejam "minimante" qualificadas, pois há o registro de pessoas que cumpriam atividades em áreas específicas da municipalidade (que certamente exigiam "alfabetização) e que ocupam nos campos de cana hierarquias distintas.

Nestas vertentes, se colocam a dimensão de um problema ampliado: a presença de milhares de trabalhadores frente a uma expressiva exploração do trabalho, ao lucro e a um pretenso constrangimento, subsidiado com dinheiro público, em razão da produção de uma "energia limpa": ambientalmente e "socialmente" correta.

\section{Trabalhadores frente às condições de trabalho.}

Eurípedes Batista Ferreira, Presidente Sindicato dos Trabalhadores Rurais de Centralina e Araporã, trabalhador rural desde a infância, avalia entrada de máquinas e os resultados destas para os trabalhadores de modo distinto dos empresários de Agronegócios.

Eurípedes: No início plantava-se cana com mão de obra (as pessoas), ganhava-se dinheiro... ganhava-se dinheiro. (Hoje), por exemplo, ganha dinheiro... é os usineiros que ganha dinheiro. Plantava cana, cortava cana, capinava cana, dava combate na cana. Hoje em dia não. Hoje em dia já tem uma máquina que planta, têm várias máquinas que colhem, têm os aviões que dão combate. Os tratoristas... quase num tem... quase tudo mecanizado e a mão de obra foi sumindo. (ALMEIDA; MORAIS; RESENDE, 2009, p.214)

Nos períodos atuais de safra estima-se que cerca de 70 mil trabalhadores cheguem às cidades do Triângulo (ALMEIDA; MORAIS; RESENDE, 2009, p.214). Estes sujeitos trazem experiências de trabalho no campo e se colocam na disputa por uma vaga nos canaviais por apresentarem resiliência ao serviço pesado, agilidades pessoais e força física (PREVITALI, MORAIS, FAGIANI, 2013). 
Edmilson, assim como milhares de outros trabalhadores, possui uma trajetória de movimentação pelo país. Ele saiu de Boca da Mata em busca de emprego como operador de máquinas nas lavouras, após passar por outras cidades foi para Tupaciguara por indicação de um amigo. Ao contrário do que planejou, trabalhou primeiramente no plantio, depois no corte da cana e ainda como condutor de tratores para só depois ter a oportunidade de ser condutor de colhedeiras.

Edmilson: [...] E olha que eu vim pra trabalhar com máquinas, operador e não consegui, passei trinta dias a toa, a empresa não me chamou; dei minha carteira pra trabalhar no campo, corta cana e planta cana. Era o que eu num tava querendo, [...] mas como eu precisava trabalhar e manter minha família, eu tive que trabalhar no corte. Falei "vou trabalhar que de lá eu tento subi"... Foi o que eu fiz, trabalhei mais ou menos três meses sofrendo, sofrendo, sofrendo, mas também num parava um minuto de correr atrás, levava currículo, falava com o supervisor, conversando com todo mundo até que deu certo [graças a Deus], fui transferido.

Denise: Você trabalhou três meses com o corte?

Edmilson: Com o corte de cana, e com o plantio, né? Corta cana mesmo, pra corta eu fui uns três ou quatro dia, depois só era plantando que a gente já tava lá no plantio né? Ia plantando, eu fiquei pelo menos uns três meses plantando cana.

Denise: E o que é trabalhar direto no campo assim?

Edmilson: Muito dolorido. A pessoa sofre muito. Eu falava toda hora... perguntava a Deus; "o que estava acontecendo?" Por que eu num saia logo dali? Por que assim é um serviço... e eu num tinha muita renda entendeu? [...] Quando eu fui cortar lá na CNA, era cana crua, cana do tamanho dessa casa aqui eu tentava abraçar uma torcera toda e corta, tentava produzir, mas logo eu cansava. Eu num guentava produzir tanto, e falava: "não isso aqui num é pra mim", entendeu? Num é porque eu num queria, eu tinha o jeito sabia fazer, mas só que eu não conseguia porque eu cansava, entendeu, mas só que eu não conseguia produzir tanto, pra ganhar bem, leva quarenta, trinta reais, [...] eu falei "não, isso aqui ...[graças a Deus] vai se um estímulo pra mim. (Edmilson, TupaciguaraMG, 2011)

A motivação dos trabalhadores é marcada por outras questões e atitudes, entre elas, há relações de vida e relações familiares:

Edmilson: É muita coisa né? Saudade aumenta, muitas vezes me perguntam, muita gente me pergunta "vale a pena?" Pra mim vale, porque eu estando lá os meus familiares num podem me ajuda...O que eles ganham lá são pra eles, num podem comprar um roupa pra mim, num podem me ajuda quando eu puder entendeu? O que eles ganham lá já é o necessário só pra eles, já é apertado, então vale a pena porque assim por longe a saudade a gente mata no telefone, final de ano eu dou um jeito eu vou lá entendeu? E a minha renda aqui graças a Deus eu ganho bem entendeu? Num ganho mal... e quando eles precisam lá...eu mando, eu ajudo[...] (Edmilson, Tupaciguara - MG, 2011)

No campo das motivações e tensões vividas entre a busca pelo trabalho e o deslocamento territorial, o deixar a família interliga-se como algo necessário ou "realidade inexorável" frente as necessidades colocadas pela vida. O evento, por outro lá, é narrado 
não somente como algo interno, plausível de sensações individuais, pois, a "partida" é vista, por alguns entrevistados, como decorrente do processo de exploração dos trabalhadores.

Denise: E por que você acha que tem essa diferença de salário de lá pra cá? Já que lá o salário é baixo.

Edmilson: Eu acho que o pessoal de lá é mais... num sei ... num eu acho que o Ministério do Trabalho lá deve ser comprado entendeu? A lei num vale muito, entendeu? Tem só no papel, num põe em prática entendeu? Os usineiros compram eles, entendeu? Eles fazem o que querem, o sindicato, [...] mais ou menos isso aí, eu num posso afirmar, mas é o que eu imagino.......porque aqui tem as leis, mas vale mais entendeu? $\mathrm{O}$ pessoal paga mais justo, ainda as empresa daqui não paga cem por cento como deveriam funciona mal, mas paga... lá paga cinqüenta por cento, se pagar! Porque eu tirara lá... o meu salário era cento e sete reais! E teve uma hora que trabalhei um mês inteiro, quando terminou a safra eu tava com trinta dias completo. Minha rescisão que é mais o salário, me pagaram setecentos reais em tudo falei "num tem lógica não!" (Edmilson, Tupaciguara- MG, 2011)

Com a expansão das usinas e da indústria no país o movimento sócio-espacial recompõe-se pelo movimento da exploração de um significativo número de trabalhadores. Difíceis de serem localizados dentro dos perfis clássicos, estes sujeitos se localizam no quadro social por suas características físicas e por precariedades historicamente atribuídas aos mesmos. No período de uma safra podem servir usineiros da cana, em outra, talvez, à colherem laranjas para grande multinacionais. Plantam eucaliptos, colhem café, constroem malha urbana e prédios em empreiteiras que contratadas por diversos governos locais, estaduais e federais.

Gabriel: você já trabalhou em outros setores?

Antônio: Eu trabalhei, eu trabalho desde os oito anos. Nessa idade eu trabalhe de chapa. Ajudando a carregar coisas. Espera os motoristas que chegavam [desde pequeno, me lembro disso], com outros mais velhos; quando os motoristas chegam a gente subia no caminhão, mostrava o lugar e ajudava no fosse preciso, Depois com 18, trabalhei no frigorífico, até ele fechar. E depois teve a cana, a usina. Foi quando eu passei para o ramo do corte... do plantio... mais do corte... mesmo. (Antônio, Campina Verde - MG, 2009)

Todos os trabalhadores entrevistados, no período de 2007 a 2011, haviam se dedicado a outras ocupações. Muitos deles passam (ainda nos dias de hoje) o ano viajando pelo país. Acompanham a sazonalidade da produção de diversas agroindústrias ou realizam serviços na cidade. O mecânico Francisco, por exemplo, narra sobre a sua experiência na construção civil, nos serviços gerais, e, até mesmo, como bituqueiro,

Denise: Francisco, fala, por favor, um pouco de você, o que você faz? De onde você veio?

Francisco: É, eu sou do Maranhão eu vim pra cá,pra Minas Gerais, pra trabalha né? Trabalha em barragem, aí vim trabalha na cimenteira, em tudo isso... aí fui e voltei pro Maranhão de novo, aí voltei, aí fui lá aí lá não deu certo aí voltei pra trás de novo pra trabalha aqui. Aí quando eu cheguei aqui de novo eu arrumei um emprego na usina, trabalhava lá aí 
eu comecei a trabalhar na roça, é... plantio de cana, plantio, corte... aí eu comecei a trabalhar bituca aí eu comecei a trabalhar de mecânico na usina, aí foi isso.[...] É homem ou mulher, porque sobra cana e o a máquina passa a carregadera pegando cai cana sobra pelo rastelo entendeu? Fica muita cana, aí tem esse pessoal que vai, os bituqueiro juntando aquele tanto que ta sobrando fazendo outro monte depois a máquina passa recolhendo, pra não fica aquela cana lá pra trás.(Francisco, Tupaciguara - MG, 2011)

Sobre o trabalho em outras regiões do país,

Denise: antes de vir trabalhar aqui em Tupaciguara, você já tinha trabalhado em alguma outra cidade?

Francisco: Já tinha ido pro Mato Grosso do Norte e do Sul. Aí no Mato Grosso do Norte eu trabalhava com soja e só isso mesmo, e do Sul a mesma coisa também. Aí quando eu cheguei pra cá trabalhei nesses outros serviços, é corte de cana, de feijão, barrage que é construção civil e agora to trabalhando na mecânica agora. Na cimenteira. (Francisco, Tupaciguara- MG, 2011)

$\mathrm{Na}$ entressafra, trabalhadores tais como Francisco, são geralmente realocados para os serviços gerais em usinas de cana,

Josefa: Ah... isso variava de preço, não é? Sempre, assim... quando a gente estava no plantio, eu tirava mil, mil e pouco. Então, varia de serviço, uma semana você está, vamos supor, no plantio, outra semana você está fazendo em uma capina, nesse caso era mais; era... era por dia. Mas, lá era mais por produção, tinha uma tal de retampa, que era tampar as cana, não é? E que eles faziam, então era, a gente ganhava por rua; o tanto de rua que você fizesse, dependendo do tanto que você fazia, você tirava trinta e cinco, trinta, trinta e cinco. Assim, os homens tiram mais que a gente, era quarenta, cinqüenta contos. No plantio lá, tinha homem que tirava até cem real por dia. Então muita gente achou ruim [fechamento da Usina de Campina Verde], sabe? Porque muitos aí... meu menino mesmo tirava dois... por mês, então... Você num acha um serviço desse aqui, pra ganhar esse tanto de dinheiro.(Josefa, Campina Verde MG, 2009)

Denise: O que o pessoal costuma pegar pra trabalhar em sua região?

Edmilson: Olha, lá a lavoura de cana que é o forte. No período da entre safra, eu no início, quando eu tinha dezoito anos trabalhei muito em cerâmica faze tijolos, fazê telha, lá faz, faz manual. Lá foi quando eu cresci na fazenda, trabalhando em cerâmica, entendeu? Aí quando eu completei meus dezoito anos eu já tava dentro da cidade aí eu falei: "não, num quero cerâmica mais vou trabalhar em usina". Então a gente na entre safra trabalhando com os particulares lá né? Na limpa de cana entendeu? Rancando muda de capim, esses serviços diversos...

Denise: E esses serviços diversos é a usina que chama pra fazer como que é?

Edmilson: Não, é terceirizado, os particulares que fornece a cana pra usina, os fornecedores...

Denise: A, então é tipo o pessoal que arrenda a terra? 
Edmilson: Isso, tem tudo, a empresa tem todo fornecedor que é cana aí planta por conta própria aí fornece pra usina né? (Edmilson, Tupaciguara - MG, 2011)

Em conjunto com dívidas contraídas com agenciadores (MARTINS, 1997; 2002), a trajetória (ou movimentação por conta da busca de trabalho) e a possibilidades de vir para "trabalhar no que for preciso" (MORAIS, 2012, p. 284), têm propiciado aos trabalhadores situações diversas de exploração, as quais se materializam em situações degradantes de vida, em precariedade de condições de saúde, escravismo (NEIVA, 1994) e mortes (ALVES, 2006).

É relevante apontar a discussão em torno da precariedade das condições desta atividade e dos esforços e desgastes vividos por tais trabalhadores, principalmente quando recebem por produção, ou seja, pela quantidade de toneladas de cana-de-açúcar colhida. A partir da leitura das entrevistas realizadas com trabalhadores que já lidaram ou lidam com o corte manual, como Edmilson e Ricardo, é possível compreendermos os significados do recebimento por produção.

Edmilson: Olha, pra quem consegue ter uma produção boa é excelente, tem muita gente que não deixa de corta cana pra trabalha com máquina, porque ele, individualmente ganha muito bem. Ele tem uma produção excelente. Mas eu se eu for trabalhar no corte de cana, num consigo produzir tanto pra ganhar mil e quinhentos mil e setecentos reais.

É cansativo, mas pela produção assim que eu ganho na faixa de oitenta, noventa até cem reais por dia...(Edmilson, Tupaciguara-MG, 2011)

Denise: Você recebe por produção então?

Ricardo: Por produção, isso. [...] se você for trabalhar por diarista assim, como diz só pela carteira... Eles assina na carteira um salário mínimo seiscentos reais... Onde você vai dá conta de trata duma família, manter você e ter alguma coisa a mais com seiscentos reais?(Ricardo, Tupaciguara - MG, 2011)

Anaílton que lida com a contratação de trabalhadores, situação legalmente impedida, comenta as dimensões do recebimento por produção para a ampliação de toneladas via corte manual,

Anaílton: Entende? Esse pessoal do Alagoas, do Maranhão, eles são muito bom de serviço. Eles vêm, eles vêm mesmo, pra trabalhar mesmo! Ali eles quer ganhar dinheiro, eles que produzi mais, porque lá na, no Maranhão, na, lá em Alagoas o salário deles lá é mais... é menor do que o nosso. Bem menor. A nossa diária aqui, de produção de cana, pra quem produz mais, eu cheguei pagar cento e vinte e seis reais ao dia, num cortador de cana. E... um pelo outro, pelo funcionários que produz mais, com o que produz menos é uma média de setenta, oitenta reais por dia. Enquanto no Maranhão um funcionário lá é quinze reais. (Anaílton, Tupaciguara - MG, 2011)

O recebimento por produção tem ampliado exponencialmente o quantitativo de corte nos últimos anos,

[...] Em 1985, o trabalhador cortava 5 toneladas diárias de cana. Na safra atual, 9,3. [...] Exige(-se) alto esforço físico uma atividade em que é 
preciso dar 3.792 golpes com o facão e fazer 3.994 flexões de coluna para colher 11,5 toneladas no dia. Nos últimos anos, mortes de canavieiros foram associadas ao excesso de trabalho. [...] O caso de um bóia-fria que morreu semanas após colher 16,5 toneladas. Não há paralelo em qualquer região com tamanho rendimento [...] (FOLHA DE SÃO PAULO, 24 ago. 2008, p. 08)

Soma-se ao aumento da produtividade a premiação com motos ou bônus salariais para os trabalhadores que obtiverem o maior rendimento no decorrer do período de corte.

Orlando: A regra é assim, vai somando, não é? Vai juntando as toneladas, ganho com uma média de dezesseis...dezessete mas tem dia que ele tira dez, tem dia que tira quarenta e aí soma na semana, e paga na média. [...] Ele ganha a moto. (Orlando, Ituiutaba - MG, 2008)

A precariedade e a exploração do trabalho nos canaviais fazem com que acordos sejam feitos entre Agroindustriais, trabalhadores, sindicatos e poder público. No Contrato de Safra, 2002, no item "Recrutamento e Seleção de Trabalhadores", temos uma idéia sobre o potencial de exploração da atividade canavieira:

O mais aconselhável é que o recrutamento de trabalhadores seja feito na própria região onde está situada a propriedade rural. Entretanto, quando isso não for possível, por escassez da mão-de-obra necessária ou adequada, o recrutamento de trabalhadores em outra região ou em outro estado deve ocorrer levando-se em consideração algumas medidas de cautela, para evitar futuros problemas trabalhistas ou mesmo de natureza penal. Sugere-se a adoção das seguintes providências e cuidados: (a) o recrutamento deve ser feito diretamente pelo futuro empregador ou por preposto (representante). A utilização de "empreiteiros" ou "gatos" é proibida por lei, gerando, inevitavelmente, situações de fraude à legislação trabalhista, além de problemas de ordem penal; (b) o empregador deverá providenciar listagem dos trabalhadores selecionados, identificando-os pelo número da Carteira de Trabalho e Previdência Social ou filiação (quando não portarem a CTPS), endereço residencial (pelo menos, o município), com dados a respeito da função a ser exercida, salário ajustado, referência à safra, identificação da empresa/empregador e sua localização. Essa relação deve ser feita em duas vias, devendo uma ser entregue à unidade mais próxima do Ministério do Trabalho e Emprego (na região ou estado de origem dos trabalhadores), mediante recibo. A segunda via dessa listagem, com o recibo, será solicitada pela Fiscalização do Trabalho; (c) o transporte dos trabalhadores (em veículo adequado ao transporte de passageiros), a alimentação e a hospedagem até o local de trabalho, além do transporte de retorno a sua origem, deverão ser custeados pelo empregador, sendo proibido qualquer desconto no salário dos trabalhadores (ver art. 207, parágrafo $1^{\circ}$, Código Penal); (d)os menores de 18 anos estão impedidos de exercer atividades rurais penosas, insalubres ou perigosas e os menores de 16 anos estão proibidos de trabalhar; (e) ao oferecer o emprego, o empregador ou preposto deverá informar previamente ao trabalhador quais são as condições reais de trabalho e de salário. Assim, o contratado, antes de iniciar as atividades, deverá estar ciente a respeito do local e para quem irá efetivamente trabalhar, onde e em quais condições será alojado (se for o caso), qual o valor da remuneração, forma de pagamento, etc. Saliente- 
se que recrutar trabalhadores com falsas promessas constitui crime (ver art. 207, parágrafo $1^{\circ}$, Código Penal). (CONTRATO DE SAFRA: MANUAL 2002, pp. 20-21)

Baseado no Código Penal Brasileiro e não somente na legislação trabalhista, a indicação acima diz respeito ao espaço de moradia e condição de trabalho, ressaltando ser "aconselhável" o recrutamento de "mão de obra" nas proximidades do local da safra. Algo que a dinâmica predatória da exploração do trabalho não tem considerado. Pois, tal como indicamos, a transposição, o endividamento, a flexibilização de atividades, entre outros fatores provenientes da movimentação temporária, instituem, por um lado, mecanismos de controle social e dominação econômica sobre milhares de trabalhadores, e, por outro, lucro para usineiros e para aliciadores de mão de obra.

A situação ganha contornos culturais, ou geográficos, quando os trabalhadores mais produtivos são identificados pelas regiões de nascimento (mesmo advindo de estados e cidades distintas, Maranhão, Piauí, Sergipe, Alagoas e outros, são tidos como "nordestinos"), e por terem "couro grosso" na realização de trabalho pesado. Estas duas dimensões são encontradas em várias entrevistas, entre outras, temos:

Gabriel: O pessoal vinha pra cá, você alugava casas. O interesse do pessoal era grande, não?

Anilton: Lógico. Com certeza, muito grande.

Arilson: Muito grande, tem muita casa alugada aí.

Anilton: O pessoal que vem de fora, também, nordestino, num é um pessoal assim... é um pessoal que já tá acostumado com o trabalho pesado, muito mais pesado, né. Então, desenvolve o trabalho muito mais do que o pessoal da cidade.

Arilson: Aí, junta as duas coisas: um que trabalhava pesado e a necessidade, né. Aí, uma coisa leva à outra. Tem o couro grosso, né. Tá mais acostumado. (Anilton; Arilton, Ituiutaba - MG, 2008)

As explorações, permeadas de inferência sobre a cultura, e as resiliências dos trabalhadores não se reduzem apenas aos circuitos próprios do trabalho, elas se expandem para outros espaços no quais a vida se reproduz. A moradia durante o tempo de trabalho, alimentação, a busca por tratamento de saúde e outros.

Os trabalhadores que se deslocam de suas regiões na busca por emprego enfrentam os problemas posteriores à sua chegada, como a falta de locais para ficar ou a inadequação destes às exigências básicas de vivência, como espaço para descanso e higiene pessoal. E se confrontam com regulamentos e distinções quando precisam utilizar os serviços públicos de cidades do Triângulo (ALMEIDA; MORAIS; RESENDE, 2009).

As situações em torno (moradia, atendimento médico, taxas sobre transporte e empréstimos) proporcionando às usinas e aos aliciadores espaços livres de atuação legalizadora sobre as relações de trabalho. Assim, há a criação de "códigos" inegociáveis propostos pelos patrões. Pois,"o capital formula, legislando particular e arbitrariamente, sua autocracia sobre os trabalhadores, pondo de lado a divisão de poderes tão proclamada pela burguesia" (MARX, 1982, p.485).

A retomada de perspectivas e de trajetórias de trabalhadores, a partir do recorte não mais restrito as categorias "cortadores de cana" e "migrantes", a nosso ver, possibilita outros conhecimentos a respeito destes trabalhadores, que historicamente tem sido vistos como desqualificados, afeitos ao trabalho pesado e mal remunerado (quando não são 
escravizados). Uma categoria pronta para ser transportada (ou se transportar), que alimenta anualmente os lucros de oligarquias de terras e de empreiteiros urbanos neste país.

\section{Considerações finais}

É momento de retornamos à questão indicada no título. Tentamos demonstrar, através de diferentes percursos, que: a) a qualificação de cortadores de cana não tem relação com a transformação tecnológica materializada nas leis contra queimadas e no processo de mecanização do plantio e colheita de cana.

b) O "desemprego" que a maquinaria causará aos cortadores de cana não será conseqüência da "baixa qualificação" de trabalhadores. Diante do modo de produção capitalista estes sujeitos são percebidos apenas como mão de obra abundante e barata, que sazonalmente empregam-se em diferentes ramos de atividades.

Por outro lado, o grau de exploração administrado na produção de bilhões de litros de bicombustível causa incômodo a setores do governo brasileiro. O Estado, por sua vez, tende a indicar ações educacionais abstratas e ampliação de programas de renda. Entretanto, as lógicas de lucro, de acumulação e de exploração permanecem inalteradas e o desconforto acaba traduzido em acordos paliativos e em pactos inócuos.

Mesmo diante de iniciativas, ainda que falhas, para transferir estes trabalhadores para outros setores e/ou qualificá-los [logicamente não estamos tratando de ações reais de formação que proporcione autonomia e conquista de direito social], percebe-se que a lógica dos salários, as condições de trabalho e a exploração do trabalho de "braceiros", tendem permanecerem inalteradas. Pois, participam do estado atual da produção de "riquezas do país".

c) Na visão do governo: "os trabalhadores formais empregados na produção da cana têm um perfil jovem [...]. Quase $91 \%$ deles têm até 50 anos, cerca de $28 \%$ entre 30 e 39 anos ou são mais jovens (cerca de $24 \%$ entre 16 e 24 anos)" (COMPROMISSO NACIONAL PARA APERFEIÇOAR AS CONDIÇÕES DE TRABALHO NA CANADE-AÇÚCAR, 2009, p.17). Ao que parece, este retrato, feito em 2009, não representa (e nem representará) um quadro perpétuo. Pois, encontramos hoje nas periferias de diversas cidades brasileiras trabalhadores rurais com mais de 50 anos não estão aposentados. Pois, por acompanharem as sazonalidades de safras, não comprovam constância nas assinaturas de carteiras de trabalho (MORAIS (b), 2012).

Frente à situação de desamparo futuro a cortadores, as repostas do presente recaem na qualificação da mão-de-obra. Entre programas de qualificação em voga em Usinas destaca-se o projeto "Renovação". Em edição da Revista IDEA NEWS, que traz em sua capa uma pirâmide sócio-econômica com uma seta indicando a subida da Classe D para a Classe A, o projeto é apresentado da seguinte forma:

O RENOVAÇÃO visa capacitar [cortadores] tanto para o trabalho em funções que são oferecidas pelas usinas, tanto na agrícola como na indústria, assim como prepará-los para trabalhar em empresas de outros setores ou mesmo abrirem o próprio negócio, conta Maria Luiza Barbosa, assessora de Responsabilidade Social Corporativa da Unica. As mesmas mãos calejadas que empunharam por anos um facão no corte de cana, hoje tentam ganhar habilidade com o lápis. Para a baiana Josefina Neres Santos, entrar numa sala de aula aos 54 anos, fazer um curso e se profissionalizar tem muito significado. "Quero ter renda", dizia ela, baixinho e com o olhar acanhado.[...] (CLIVONEI, ago. 2011, pp.8-9) 
d) Frente ao que fora aqui apresentado retornamos à questão: deveriam os cortadores se qualificar? Estranhamente, ao buscarmos projeções no social que dessem conta de nos orientar a este respeito, nos deparamos com respostas e ações coletivas que nos aproximaram das preocupações do próprio Hobsbawm (2000).

Cerca de 90 mulheres da Vila Campesina, composta pelo Movimento dos Trabalhadores Rurais Sem Terra (MST), Movimento dos Atingidos por Barragens (MAB) e Movimento dos Pequenos Agricultores (MPA), acompanhadas de crianças, realizaram na manhã desta quinta-feira (3), uma manifestação no quilômetro 115 da BR-050, entre Uberlândia e Uberaba. A pista ficou bloqueada nos dois sentidos por mais de duas horas, o que provocou um congestionamento de veículos de cerca de seis quilômetros. A Polícia Rodoviária Federal (PRF) acompanhou o protesto. De acordo com Ana Maria de Lima, uma das integrantes da manifestação, o objetivo da ação é alertar para o uso de agrotóxicos na região do Triângulo Mineiro e Alto Paranaíba e também comemorar o Dia Internacional da Mulher. Segundo Ana Maria, durante a semana, foi realizado o Seminário Estadual da Vila Campesina na Fazenda Inhumas, que promoveu palestras para as mulheres sobre utilização de agrotóxicos. "Hoje é o encerramento do Seminário e, após estudar sobre o agrotóxico, que ainda é muito utilizado na região do Triângulo Mineiro e do Alto Paranaíba, estamos manifestando em defesa da agricultura, da terra e do meio ambiente", disse. Além do protesto com bandeiras e faixas, as manifestantes realizaram o corte de canas em fazendas próximas à Usina Vale do Tijuco, com o objetivo de mostrar, segundo Marili Zacarias, uma das organizadoras da manifestação, que a monocultura não traz benefícios para a região. (CORREIO DE UBERLÂNDIA, 03 de março de 2011. p.A2)

Somados a diferentes ocupações de terra no Triângulo e em outras regiões de Minas, que são realizadas com a presença de cortadores e trabalhadores sazonais (ALMEIDA, MORAIS, 2012) temos percebido que a ação inicial frente à mudança no corte da cana não é a da qualificação. A ação de parte significativa de trabalhadores gira em torno de mobilizações e de organizações na luta pela terra.

No interior destes movimentos sociais, a qualificação existe em meio a simbolismos e a temáticas distintas às da produção e do lucro dos empregadores. Há nessas ambiências, principalmente no tocante às "práticas politizadoras", significativas ações "educadoras" (VENDRAMINI, 2007, p. 1403) voltadas à preservação da agricultura familiar e a crítica à monocultura.

Célia Regina Vendramini, pesquisadora que possui amplo estudo sobre o Movimento dos Trabalhadores Sem Terra, compreende que tais ações propõem um "luta radical que se manifesta no questionamento da ordem existente, além da construção de grupos coletivos como tentativa de superação da forma de trabalho individual na agricultura" (2007, p. 1403).

Estamos cientes do fato de que os trabalhadores das lavouras conhecem os riscos dos agrotóxicos, da exploração do trabalho e da monocultura - enquanto modo de produção que limita atividades e a sobrevivência de suas famílias. Entretanto, precisamos ainda compreender os laços e as pressões sociais que hegemonicamente alimentam as noções sobre a qualificação individual, mercadológica; que faz com que trabalhadores concorram entre si por um lugar ao sol. 
Para tanto, precisamos também nos qualificar enquanto sujeitos e pesquisadores, nas ações, perceptivas, sonhos, organizações e mobilizações dos próprios trabalhadores, para, por fim, melhor compreendê-los.

\section{Referências}

ALMEIDA, Paulo Roberto de; MORAIS, Sérgio Paulo. Em movimento: trabalho em canaviais e trajetórias de trabalhadores no Triângulo Mineiro nas últimas décadas. Revista Mundos do Trabalho, v.4, 2012, pp. 146-162

; MORAIS, Sérgio Paulo; BARBOSA, Tulio. Histórias, memórias e cidadania: notas de pesquisa sobre os fluxos migratórios de trabalhadores para o Triângulo Mineiro. In: BOSI, A. P.; VARUSSA, R. J.. (Org.). Trabalho e Trabalhadores na contemporaneidade: diálogos historiográficos. 1ed.Cacavel: Edunioeste, v.1, 2011, pp. 143-166.

; MORAIS, Sérgio Paulo; RESENDE, Renata. Entrevista com Eurípedes Batista Ferreira Presidente do Sindicato de Trabalhadores Rurais e Agricultores Familiares de Centralina e Araporã. Revista Historia \& Perspectivas (UFU), v. 41, 2009, pp. 213-227.

ALVES, Francisco. Por que morrem os cortadores de cana? Revista Saúde e Sociedade. v.15, n.3, set.-dez. 2006, pp. 90-98.

CLIVONEI, R. Programas de formação CAPACITAM E TRANSFORMAM VIDAS na agroindústria do açúcar e etanol. In: IDEA News. ANO 11- $\mathrm{N}^{\circ} 123$, janeiro de 2011, pp. 89.

ENGELS, Friedrich. Carta de Friedrich Engels a Bloch, 21-22 set. 1890. In: MARX, Karl; ENGELS, Friedrich. Obras Escolhidas. São Paulo: Alfa-Ômega, v. 3. 1986.

FRIGOTTO, Gaudêncio; CIAVATTA, Maria. Educar o trabalhador cidadão produtivo ou o ser humano emancipado?. Trab. educ. saúde [online]. vol.1, n.1, 2003, pp. 45-60.

GENTILI, Pablo. Neoliberalismo e educação: manual do usuário. In: SILVA, Tomaz Tadeu da; GENTILI, Pablo. (Org.) Escola S. A. Quem ganha e quem perde no mercado educacional do neoliberalismo. Brasília: CNTE. 1996, pp. 09-49.

HADDAD, Sérgio; GRACIANO, Mariângela. Educação: direito universal ou mercado em expansão. São Paulo Perspec., São Paulo, v. 18, n. 3, Set. 2004, pp.6771.<http://dx.doi.org/10.1590/S0102-88392004000300008> Acessado em 26 de maio de 2012.

HOBSBAWM, Eric. Deveriam os pobres se organizar? Mundos do trabalho. $3^{\text {a ed, Rio }}$ de Janeiro: Paz \& Terra, 2000, pp. 399-416.

JANTSCH, Ari Paulo. Pequeno (ainda) agricultor e racionalidade educativa. $1^{\circ}$. ed. Florianópolis: Núcleo de Publicações (UFSC/CED), 2001. 
LIMA NETO, Newton (org.). Avaliação do Plano Nacional de Formação Profissional: Relatório de Análise das Avaliações dos PEQs/97. São Carlos: FAI/UFSCar. 1998.

MARTINS, José de Souza. A escravidão na sociedade contemporânea: A reprodução ampliada anômala do capital e a degradação das relações de trabalho. In: . A sociedade vista do abismo: novos estudos sobre exclusão, pobreza e classes sociais. Petrópolis: Vozes. 2002, p. 151-162.

Fronteira. A degradação do outro nos confins do humano. São Paulo. Hucitec, 1997.

MARX, Karl. O Capital (livro 1, vol. 1) São Paulo. Didel, 7ª edição, 1982.

MORAIS, Sérgio Paulo. Trabalhadores agroindustriais: estrutura e processo histórico no Triângulo Mineiro (1980-2012). SÆCULUM - REVISTA DE HISTÓRIA [26]; João Pessoa, jan./jun. 2012.

(b). Incluídos? Pobreza e políticas compensatórias em um Brasil rico. Saarbrücken. Editorial Académica Española, 2012. 297p

NEIVA, I. E. G. Os escravos no Brasil. In: CPT - COMISSÃO PASTORAL DA TERRA. Conflitos no campo: Brasil 1994. Goiânia: CPT, 1994, pp.22-30.

PREVITALI , Fabiane Santana. ; MORAIS, Sérgio Paulo; FAGIANI, Cílson. Ethanol Workers in Brazil: the other side of wealth. In:. Workers of the world - International Journal on Strokes and Social Conflicts / Special Issue - Global labour history. Vol. I, $\mathrm{n}^{\circ} 3$. May 2013, pp. 227-244. Disponível em: < http://www.workersoftheworldjournal.net/images/WW_3.pdf $>$. Acesso em 14 maio de 2013.

SEGNINI, Liliana Rolfesen Petrlli. Educação e Trabalho: uma relação tão necessária quanto insuficiente. São Paulo em Perspectiva. São Paulo, v. 14, 2000, p. 72-81.

SOUZA, A.G.; CLEPS JR., J. O desenvolvimento da agroindústria canavieira no Triângulo Mineiro e seus impactos sobre a mão-de-obra e a produção de alimentos. In: Anais do XIX Encontro Nacional de Geografia Agrária, São Paulo, 2009, p. 1-16. Apud, CLEPS JR., J. Concentração de poder no agronegócio e (des)territorialização: os impactos da expansão recente do capital sucroalcooleiro no Triângulo Mineiro. Caminhos de Geografia. Edufu. Uberlândia v. 10, n. 31.Set/2009, p. 249 - 264.

TEIXEIRA, Éber Mariano. "Amanhã é outro dia: falas, memórias e outras histórias de trabalhadores cortadores de cana na região Noroeste do Estado de São Paulo. In: MOREIRA, Vagner José; NARDOQUE, Sedeval; PERINELLI NETO, Humberto (Org.) Noroeste Paulista: práticas e movimentos sociais, trabalhadores e experiências. 1. ed. São Paulo: Outras Expressões. v. 1, 2013, pp. 217-228 
VENDRAMINI, Célia Regina. Pesquisa e movimentos sociais. Educação e Sociedade, Campinas, vol.28, n. 101 set./dez. 2007. pp. 1395-1409.Disponível em: <http://www.cedes.unicamp.br> acesso em: 25 abril de 2013.

Entrevistas:

Anilton; Arilson. 2008. Ituiutaba - MG. Entrevista concedida a Denise Nunes De Sordi, Ezequiel de Araujo Martins, Gabriel Pimentel de Melo e William Mariano Santos.

Antônio. 2009. Campina Verde - MG. Entrevista concedida a Gabriel de Oliveira.

Edmilson F. da S. Tupaciguara - MG. 14 jul. 2011.Entrevista concedida a Denise Nunes De Sordi.

Francisco. 14 jul. 2011. Tupaciguara - MG. 14 jul. 2011. Entrevista concedida a Denise Nunes De Sordi.

Josefa. 2009. Campina Verde - MG. Entrevista concedida a Gabriel de Oliveira.

Ricardo. 14 jul. 2011. Tupaciguara - MG. 14 jul. 2011. Entrevista concedida a Denise Nunes De Sordi.

Orlando. 14 jul. 2011. Tupaciguara - MG. 14 jul. 2011. Entrevista concedida a Denise Nunes De Sordi.

\section{Jornais:}

ÁLVARES, Matheus O POPULAR. Trabalho escravo: Operação resgata 39 trabalhadores em Goiás. 18 out. 2011. Disponível em: <http://www.opopular.com.br/cmlink/opopular/editorias/geral/opera\%C3\%A7\%C3\%A3oresgata-39 trabalhadores-em-goi\%C3\%A1s-1.50013> . Acesso em: 24 out. 2012.

FERNANDES, Arthur. Canápolis. Bituqueiras na lida da cana. CORREIO DE UBERLÂNDIA(a), 31 maio 2009, p. A.6.

FERNANDES, Arthur. Canápolis. Um certo toque feminino não poderia faltar. CORREIO DE UBERLÂNDIA (b), 31 de maio de 2009, p. A6.

REDAÇÃO. Mulheres fazem manifestação na BR-050.CORREIO DE UBERLÂNDIA, 03 de março de 2011, p. A2.

MAGALÃES, Mário; SILVA, Joel. FOLHA DE SÃO PAULO. O submundo da cana. 24 ago. 2008, p.08.

\section{Outras fontes:}


AGÊNCIA MINAS. Protocolo Regula queima da cana-de-açúcar em Minas. Disponível em: <http://www.agricultura.mg.gov.br/noticias/719> 26 ago. 2008, acesso em 25 abr. 2013.

BONSUCRO - Better Sugar Cane Initiative. Cert-ID do Brasil Certificadora Ltda. $<$ http://www.cert-id.com.br/certification/bsi-better-sugar-cane-initiative/>.2008-2012. Acesso em 03 nov. 2011.

COMPROMISSO NACIONAL PARA APERFEIÇOAR AS CONDIÇÕES DE TRABALHO NA CANA-DE-AÇÚCAR. Mesa de Diálogo para Aperfeiçoar as Condições de Trabalho na Cana-de-Açúcar. 25 jun. 2009. Disponível em: <http://www.secretariageral.gov.br/.arquivos/publicacaocanadeacucar.pdf > . Acesso em 29 ago. 2011.

CONTRATO DE SAFRA: MANUAL. Secretaria de Inspeção do Trabalho - SITBrasília : TEM/SIT, 2002.

JORNAL DA CIÊNCIA. ENALTA é única brasileira em ranking internacional de inovação.7 mar. 2013. Disponível em: <http://www.jornaldaciencia.org.br/Detalhe.jsp?id=86098>. Acesso em: 8 maio 2013.

MINISTÉRIO DO TRABALHO. Educação Profissional. PLANFOR. Formando o cidadão produtivo. Brasília: MTb/ SEFOR. (s/d).

\section{Notas}

1 Doutor em História Social, professor associado da Universidade Federal de Uberlândia. Atua nos programas de graduação e pós-graduação em História, Linha Trabalho e Movimentos Sociais. Membro do Núcleo de Pesquisa e Estudos em História, Trabalho e Cidade - NUPEHCIT e Grupo de Pesquisa Trabalho, Educação e Sociedade - GEPTE .E-mail: moraissp@yahoo.com.br.

2 Mestranda do Programa de pós-graduação em História da Universidade Federal de Uberlândia, Linha Trabalho e Movimentos Sociais. E-mail: denisends@gmail.com.

\footnotetext{
${ }^{3}$ Nos referimos sobretudo aos municípios de Uberlândia, Araguari, Monte Alegre de Minas, Tupaciguara, Araporã, Canapólis, Capinópolis, Ituiutaba, Santa Vitória, Uberaba e Delta. Disponível em: <http://www.lagea.ig.ufu.br/xx1enga/anais_enga_2012/eixos/1483_1.pdf>. Acesso em 29 abr. 2013.

${ }^{4} \mathrm{Na}$ visão dos autores (FRIGOTTO, CIAVATTA, 2003, p.52): “O Plano Nacional de Qualificação do Trabalhador (PLANFOR) consagrou o termo 'formação do cidadão produtivo segundo algumas diretrizes básicas [Ministério do trabalho, MTB, s.d, apud, op cit]: consolidação da estabilidade econômica, desenvolvimento com equidade social, modernização das relações capital/trabalho, construção da cidadania, universalização da educação básica de qualidade, educação profissional contínua em vista da complementaridade entre a educação básica e a educação profissional, geração e melhor distribuição de renda em vista de mais e melhores empregos, e empregabilidade para o acesso e permanência ao mercado de trabalho". Sobre avaliação do PLANFOR, (FRIGOTTO, CIAVATTA, 2003, p.58): "ver LIMA NETO, 1999 e CIAVATTA, 2000".
}

Recebido em abril-13

Aprovado em maio-13 